\title{
Computer Modeling as a Means of Implementing Project-Based Activities in STEM-Education
}

\author{
Vasyl Kovalchuk ${ }^{1}$, Lyudmila Shevchenko² ${ }^{2}$, Tetiana Iermak ${ }^{3,4}$, Kateryna Chekaniuk ${ }^{1}$ \\ ${ }^{1}$ Oleksandr Dovzhenko Hlukhiv National Pedagogical University, Hlukhiv, Ukraine \\ ${ }^{2}$ Shostka Educational Complex: Specialized School of I-II Degrees-Lyceum of Shostka Town Council of Sumy region, Shostka, Ukraine \\ ${ }^{3}$ Institute of Pedagogy, The National Academy of Pedagogical Sciences of Ukraine, Kyiv, Ukraine \\ ${ }^{4}$ Educational institution Lyceum 157, Kyiv, Ukraine \\ Email: v.i_kovalchuk@ukr.net
}

How to cite this paper: Kovalchuk, V., Shevchenko, L., Iermak, T., \& Chekaniuk, K. (2021). Computer Modeling as a Means of Implementing Project-Based Activities in STEM-Education. Open Journal of Social Sciences, 9, 173-183. https://doi.org/10.4236/jss.2021.910013

Received: September 22, 2021

Accepted: October 18, 2021

Published: October 21, 2021

Copyright $\odot 2021$ by author(s) and Scientific Research Publishing Inc. This work is licensed under the Creative Commons Attribution International License (CC BY 4.0).

http://creativecommons.org/licenses/by/4.0/ (c) (i) Open Access

\begin{abstract}
The issues of application of projects implemented with the help of computer modeling within the framework of STEM-education, which is fundamentally different from traditional teaching, are considered. This system creates conditions for development and improvement of analytical and creative abilities of students, gives them an opportunity to try themselves in teamwork, and develops their independence in acquiring new knowledge. This type of activity contributes to the integration of academic subjects, the formation of students' skills of using modern technologies and modeling in their activities. Independent creation of models gives students the opportunity to better understand the basic properties of objects, phenomena, processes, their studied components, and the relationship between them. The study of models develops in children the skills of analysis, synthesis, critical thinking, and methodical approach to content realization by means of computer modeling within the framework of project-based activities. The results of the research into the use of computer modeling as a means of implementing project activities in STEM-education are presented. The conception of the research was cross-cutting skills common for all key competencies would be formed among those who receive education after the STEM-projects implementation. Cross-cutting skills are formed in all subjects and are common to the key competencies. In the course of the study we have come to the conclusion that after the implementation of STEM-projects the distribution of cross-curricular skills common to all key competencies of education applicants has changed.
\end{abstract}

\section{Keywords}

STEM-Education, Project-Based Activities, Computer Modeling, Leadership 


\section{Introduction}

The scientific and technical and socio-economic development of Ukraine in the con-text of globalization is aimed at achieving European standards of living. Only effective interaction of economy, science, education and the use of innovative technologies in all spheres of society will allow achieving the intended goal.

Modern development of economy, science and technology requires future specialists to possess absolutely new competencies on the edge of several branches, in particular science, technology, engineering and mathematics (Morse et al., 2018). This global trend is related to the growing importance of human resources for the complex technological world, where the importance of raw material resources is reduced due to new economic and environmental solutions based on nano- and digital technologies (Schmiger \& Vasilenko, 2017). In this regard, there is a need for specialists with innovative thinking and potential, who are able to solve non-standard problems and offer modern engineering solutions based on their ideas and hypotheses. Therefore, the education system should meet the requirements of the present time and the needs of the individual, quickly responding to dynamic changes in society.

The aim of the study is to implement project-based activities by means of computer modeling to implement STEM-education.

\section{Presentation of the Main Research Results}

\subsection{Literature Review}

One of the ways to solve this problem is the spread of STEM-education (S-science, $\mathrm{T}$-technology, $\mathrm{E}$-engineering, $\mathrm{M}$-mathematics), where the leading place is occupied by practice that combines branched knowledge into a single whole Yakman, G. (2019).

The problems and prospects of STEM-education are considered in their studies by such scholars as Georgette Jackman, George Lucas, Jonathan W. Gerlach, N. Balik, S. Galata, N. Goncharova, O. Korshunova, N. Morse, A. Strizhak, and others. However, the practical issues of implementing STEM education by means of computer modeling require further research and scientific development.

STEM-education is fundamentally different from traditional education, it creates conditions for development and improvement of analytical and creative abilities of schoolchildren, gives them an opportunity to try themselves in teamwork, develops independence in obtaining new knowledge.

Theoretical analysis of the sources on STEM-education allowed us to identify three key features that distinguish it from the traditional educational system. The essence of them is the following: 
- firstly, thanks to STEM-education children have more time and opportunities for independent preparation, they learn to identify problems and search for their solutions autonomously by active purposeful and assimilated activity;

- secondly, through participation in teamwork, participants in the educational process have the opportunity to share their analytical and creative findings and mistakes with other team members; students solve problems and create projects together;

- thirdly, STEM-education cultivates and encourages mutual support and assistance in solving educational tasks.

One of the key differences between STEM-education and traditional education is the development of learning skills as opposed to memorization of material, which is more typical for most educational institutions. Modern students need independent work, the ability to generate new ideas, work in a team of peers, solve cognitive problems, and search for errors in their activities with their subsequent correction (Goncharova \& Patrikeeva, 2020). All this is the basis of STEM-education, making it one of the most important trends in modern education.

Thus, we can confidently say that STEM-education contributes to the development of leadership skills of students, which are necessary for the young generation in any field of activity.

STEM-education creates a solid foundation for successful further education and mastering many areas in professional activity if it is implemented competently and comprehensively. A distinctive feature and the main idea of STEM-education is the understanding that not only theoretical but also practical (applied) knowledge is important for student development and learning, as well as independence in achieving it. It follows that the STEM approach is not so much a certain teaching method as a certain way of thinking. Students will be equipped not only with knowledge, but also with the ability to solve problems, the algorithm of overcoming difficulties with the support of interdisciplinary knowledge and joint work will become clear to them (Korshunova et al., 2020).

As evidenced by the results of the analysis of scientific research, modeling at school can be used in the study of any subject. In this case, scientists are primarily focused on the creation of models that do not require additional tools, instruments and materials. For example, in their research T. Kramarenko and A. Pilipenko (Kramarenko, Pylypenko, \& Zaselskyi, 2019) consider the possibility of using systems and Gran GeoGebra in the educational process in order to create mathematical models for solving problems in the classroom (Kramarenko, Pylypenko, \& Zaselskyi, 2019).

\subsection{Method}

The study was conducted on the basis of the following educational institutions: Educational institution Lyceum 157 of Kyiv, Shostka educational complex: specialized school of III degrees-lyceum of Shostka town council of Sumy region 
and Bila Tserkva general education school I-III stages of 18 Bila Tserkva town council of Kyiv region.

During the year, the educational institutions implemented STEM projects in different areas. Students in grades 9 and 10 participated in the study. The total number of students who participated in the experiment was 102. Teachers of computer science, mathematics, physics, chemistry, and labor training were also involved.

\subsection{Modeling in STEM}

The educational system strives to solve the main educational task-to develop students' abilities. This becomes possible when working within the framework of STEM-education, thanks to the view of the learning process and education in general can be changed. STEM-education, as mentioned above, emphasizes the independence of participants in the educational process in obtaining new knowledge, so that students have the opportunity to improve and strengthen willpower, develop creativity, communication skills during teamwork.

The key feature of STEM education, which should be emphasized, is the interaction of participants in the educational process in terms of teamwork, it is the joint activity that is relevant to the activities in the process of creating and defending projects. Thanks to project-based activity students get an opportunity to activate the creative, emotional, creative component of their personality. Project-based activities can be carried out to build different models in any industry.

Modeling is one of the important tools for forming the life competencies of the modern student. When modeling, comprehensive analysis of created, search for alternative solutions and improvements, skills of logical, creative, critical thinking are formed; pupils get an opportunity to highlight the main features and characteristics of modeling objects. At the same time, educational institutions experience difficulties when choosing programs and tools for the implementation of this direction in the conditions of practical activity with students.

Building a computer model is the technology that helps observe and study phenomena and processes in dynamics, perform multiple tests of the model, obtain various quantitative indicators in numerical or graphical representation, in particular those that require performing complex, numerous or time-consuming calculations (Morse et al., 2020).

Focusing on the modern labor market, educational specialists radically revise curricula directly related to the preparation of the younger generation for new roles in society, mastering of the new generation of such technologies, knowledge, skills, which will meet the needs of a digital society in the future. That is why today the approach to education has changed, as well as the requirements for the acquired knowledge of students. Schools are introducing research activities, through practice-oriented learning to help motivate students to make new discoveries. Teachers began to resort to the practice of STEM-education, which is based on midsubjects, the integration of certain scientific branches into a sin- 
gle learning system to solve specific problems from real life (Balik et al., 2018).

STEM-education is organized in such a way that students have an opportunity to practically apply theoretical knowledge in the process of implementation of their educational-research and project-creative activities, and doing it consciously.

Thanks to STEM-education students can develop in several subject areas at once-computer science, physics, technology, engineering and mathematics, realizing that there is an applied nature to the investigated, boring, theory: STEM-skills and scientific-research, engineering, mathematical and design technologies (Andrievskaya \& Bilousova, 2017).

The changes taking place in today's digital society increase the requirements for the level of digital competencies of a specialist. Under these conditions, the development of electronic forms of learning, the use of digital learning tools (computers, tablets and others) to form elementary digital skills (competencies) and skills for the implementation of project activities becomes relevant.

\subsection{Design in STEM}

The essence of STEM technology is that it is based on the engineering approach to invention. To get a product, it is necessary to design it, i.e. to describe or visualize an object that does not yet exist, which should be invented and presented (Balik et al., 2018).

The first step in designing is to set the problem. Next, it is necessary that the result corresponds to a certain goal. For this purpose, research is carried out, knowledge from different areas is applied, which are combined to obtain effective solutions. In the process of such activity, the student's understanding of the world is formed. STEM technology successfully complements school education in technical subjects, immerses students in understanding the essence of the subject and its application in practice (Balik et al., 2018).

Considering the project activity as STEM-learning, it is reasonable to highlight the main components of the project as a whole and the stages of organization of the specified activity by means of computer modeling.

First of all, the choice of the project topic should be relevant, taking into account the development of modern technologies and student's interests. First of all, the project should be interesting to perform and be in the circle of student's interests, and at the same time become an example for cognition of the surrounding reality.

After selecting a project topic, a project plan is usually prepared. It is necessary to prepare a list of questions that the student wants to get answers to during the project, as well as to determine the final goal of the content. Note that the goal may change or transform as the project progresses. And the list of questions may also significantly expand or, on the contrary, narrow. The result of the project depends on the ability to properly plan the project.

While working on the project, it is advisable to define 5 criteria that the goal 
should meet: specificity, measurability, achievability, relevance, deadline.

Competent planning will help to meet certain time limits, provide the project with resources, program the team to achieve the goal, identify the range of support resources, provide support partners who can back up and help cope with problems in case they arise.

After defining the research questions, it is necessary to begin to make a plan for finding answers and defining the object and subject of the research, then it is necessary to choose research methods, to put forward a hypothesis, to improve the research plan. It is obligatory to conduct hypothesis testing in the course of the study. The next stages are a description of the process, registration of the results, formulation of conclusions and evaluation of the results. It is necessary to determine the practical relevance, that is, the area of application of the solution found.

The above steps describe a standard work plan. STEM technologies appear when students start working directly on the project.

After determining the range of issues to be solved, it will be obvious that the student will search for information on the Internet, studying the information resources available to them. Then the information will be processed, transformed.

\subsection{Computer Modeling in STEM}

The essence of computer modeling in project activities is to find quantitative and qualitative results using the available model. Depending on the type of computer model (mathematical, simulation, graphic), the appropriate software tools are used.

Teaching only in the form of information transfer has lost its meaning, because today any student can go on the Internet and find the necessary information about the subject of research. It is at school that children have to learn to operate with information, to put it into practice. The school cannot stand aside from the trends that dictate the development of new digital technologies.

After collecting information and determining the range of additional questions or unresolved problems, the transition to the implementation of the practical part of the project. It should also be divided into two stages: calculation (mathematical) and practical (engineering).

At the computational stage the theoretical aspects of the project are usually calculated, at the practical stage-the construction of a computer model takes place.

STEM is more than school lessons. Through this system of education, students can see how what they are learning is embedded in their future and the future of the world. This generates in them an interest that is sometimes lacking when learning new things. Quite often children feel that school curricula are completely disconnected from the real world. In order for students to be able to learn the basics of any science and higher technology with interest, digital trends need to be applied. The task of the school is to create a basis that will help both 
in learning and in everyday life, to promote the ability to solve problems, guided by a scientific approach. It is also important to show how theoretical knowledge can be applied to life: this will make science and programming exciting and useful. For example, students can learn how to model bridges, launch rockets, build gliders, direct jobs, and much more in the classroom. In most cases, they work in teams. Many experiments are conducted in the lessons: this enables them to demonstrate the material more clearly and makes the lessons more interesting.

In fact, computer modeling plays an important role in modern society and is widely used in marketing, architectural design and cinematography, not to mention industry. Computer models are so incorporated into all areas of human activity that we can no longer imagine the present without them.

Teaching students through computer modeling should increase students' interest and motivation in project activities. Primary in this case is children's obvious fascination with games and computers. It is necessary to teach modern schoolchildren to perceive gadgets not only as sources of entertainment, but also as a working tool. In addition, thanks to an interesting form of application in the educational process is more effective awareness of interdisciplinary connections.

Today 3D-modeling is quickly gaining popularity, it allows you to create any model in volumetric format. Thanks to popularization, 3D-modeling has moved to a new level and has become more necessary than ever. It is worth noting that the creation of $3 \mathrm{D}$ models is available to all students, as there is a fairly large amount of free software needed to create it.

3D models can be used in the study of such subjects as physics, chemistry, astronomy, geography and others. For example, the use of computer modeling in physics classes allows creating kinematic models and demonstrating particle interactions.

Today, participants in the educational process can use open educational Internet resources to supplement traditional teaching tools. There are a large number of free educational sites, virtual laboratories, simulators, interactive museums, which make conducting project activities available and the learning process creative. Thus, the use of high-quality educational Internet resources, on the one hand, creates a positive motivation for students to be concerned with STEM education and, on the other hand, contributes to collective learning activities of all participants in the educational process.

With the help of free services for chemistry lessons you can create large-scale 3D models of chemical substances and compounds, devices for chemical reactions, etc. In biology classes, you can take a trip to human vessels and examine virtual models of cells. In geography classes, you can model the relief of the Earth's surface and create models of lithospheric plates. And in literature lessons, to create a computer model similar to a three-dimensional graph, the tops of which will indicate the characters of a work of fiction, and the different-colored edges of the graph of different lengths will indicate the relationships between the characters. Created on the basis of this computer model 3D animation 
will help to trace the course of the plot of the work in dynamics, which will allow better understanding the opinion of its author (Romanyuk \& Poida, 2019).

The last part of the work on any project is the mathematical stage: it is necessary to collect data, make calculations and prepare specific recommendations on the created model and its application.

Based on the fact that in the near future there will be a sharp increase in demand for engineers, specialists of high-tech industries, and most professions will be associated with new technologies, the learning process should contain the study of computer technology and work with it. Thus, the process of project work combines all branches of knowledge within the framework of STEM-education.

\subsection{Benefits of STEM Education}

So, let's identify the advantages of STEM education.

The first significant advantage is integrated learning by topics rather than by subjects. STEM-education combines interdisciplinary and project-based approach, the basis for which is the integration of natural sciences into technology, mathematics, engineering creativity, etc. (Lucas, Cooke, \& Friis, 1999). It is very important to teach science, technology, engineering, and mathematics in an integrated way, since these areas are closely interconnected in practice.

The next advantage is the application of scientific and technological knowledge in real life. That is, STEM education through hands-on activities demonstrates to students the application of scientific and technical knowledge to a specific project, resulting in the creation of a prototype of a real product with their own hands.

STEM technology also develops critical thinking and problem-solving skills necessary for overcoming challenges students may encounter in life.

Students have the opportunity not only to create various real products, but also to test and improve them. They, by solving all problems on their own, reach their goal. For students it is inspiration, victory, adrenaline, and joy. After each victory they become more and more confident in their abilities.

STEM projects are characterized by active communication and teamwork. At the stage of discussion, a free atmosphere is created for discussion and expression of opinions. They are so free that they are not afraid to express any of their thoughts, they learn to speak and present. The participants of the educational process communicate all the time with the teachers and their teammates, in which cooperation is assumed, related to the distribution of roles, material, functions and individual actions.

STEM learning consists of six stages: question (task), discussion, design, construction, testing, and improvement. These stages are the basis of a systematic design approach. In turn, the coexistence or co-dependent use of different possibilities is the basis for creativity and innovation.

Thus, the simultaneous study and application of science and technology can create many innovative projects. 


\subsection{Implementation}

As an example, consider the STEM project "Creation of the Smart House Model". The educational purpose of the project is to create a model of a house of the future, to deepen the knowledge of students in the subjects of computer science, mathematics, physics, chemistry, labor education by updating knowledge on the issue of energy conservation and applying it to solve the problem.

During the implementation of the STEM project, students explore the development of the problem and analyze it in the context of modern life. In a natural science lesson, students investigate the current state of energy resources that humans consume. Using educational materials prepared by the teacher with the help of electronic encyclopedias and educational Internet resources the students make analysis and calculations, on the basis of which they draw conclusions about the necessity of conservation and saving such energy resources as water, electric power and gas. Realization of the STEM-project also provides for work of pupils outside of school, children investigate the state of consumption of energy resources at home. During the study of the state of the problem children set the problem to be solved during the project (reduce consumption of energy resources).

The students think about their vision of Smart Home features: powering the model home, configuring the necessary sensors, automatically closing and opening doors and windows, automatic lighting and alarms.

With the help of computer modeling they create a $3 \mathrm{D}$ model of the house as a basis for creating a prototype product. In the lessons of labor education they develop a project of the house of the future. Experiments with sensors for their proper setup are conducted in physics and chemistry lessons. And the accuracy of architectural calculations is checked at math lessons. At computer science lessons they program the Smart House model, check the results of the project and draw conclusions. The results of the project are demonstrated in the form of charts and presentations. Thanks to the implementation of the project, the children managed to optimize the consumption of resources and save money for electricity, gas, and water.

\subsection{Discussion}

STEM education is not only a method of learning, but also a way of thinking. Students receive knowledge and immediately learn how to use it. So when they grow up and face real-world problems in the real world, be it environmental pollution or global climate change, they understand that such complex issues can only be solved by drawing on knowledge from different areas of knowledge and by working together all together.

Analysis of the results of learning achievements after the implementation of STEM projects showed the formation of cross-cutting skills common to all key competencies among those who receive education. Cross-cutting skills are formed in all subjects. They are common for all competencies. Cross-cutting 


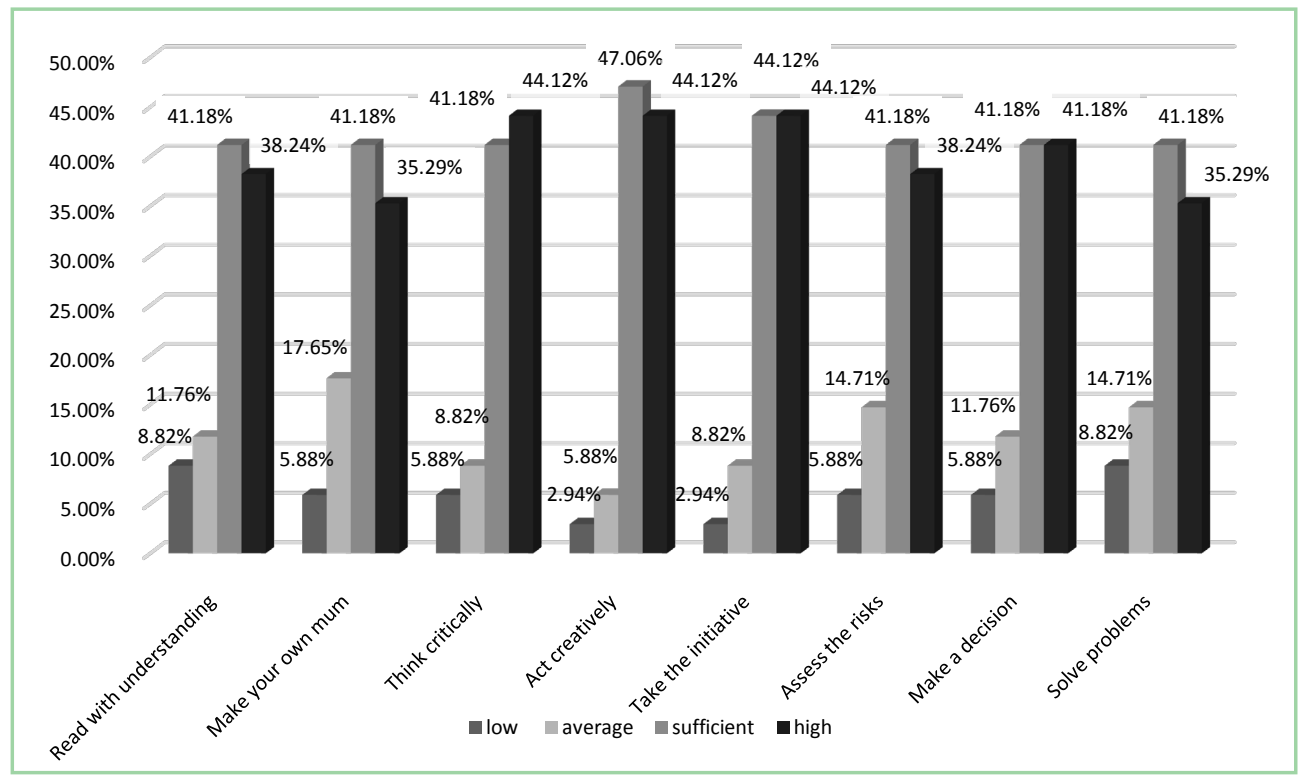

Figure 1. Formation of cross-cutting skills common to all key competencies of students.

skills include the ability to read with comprehension, express own opinion orally and in writing, think critically and systematically, act creatively, show initiative, be able to justify a position logically, manage emotions constructively, assess risks, make decisions and be able to solve problems.

Teachers scored students on each criterion and determined that $80 \%$ of students showed above-average proficiency in these skills (see Figure 1).

Thus, the introduction of project-based activities by means of computer modeling within the framework of STEM-education promotes the formation of skills of independent, research, exploratory activity of each student and increases the formation of subject competencies.

\section{Conclusion}

The paper presents the results of the study of computer model used as a means of project-based activities implementation in STEM-education, the concept of which was that cross-cutting skills common to all key competencies of education applicants would be formed after the implementation of STEM projects. The analysis of the results of learning achievements after the implementation of STEM-projects showed the formation of cross-cutting skills common to all key competencies in $80 \%$ students at the level above average.

In today's society the issue of STEM-education is not only the work on an individual educational project as part of individual work, but also the wide implementation of modern learning technologies. The main peculiarity of STEM-based lessons is building the learning process in such a way that students use knowledge from different subjects. Such kind of activity promotes the integration of academic subjects, formation of students' skills to use modern technologies and modeling in their activity. Independent creation of computer models gives students an opportunity to better understand the basic properties of objects, phe- 
nomena, processes, their studied components, the relationships between them. Their study shapes students' skills of analysis, synthesis, evaluation, critical thinking, and methodological approaches to implementing the project by means of computer modeling.

STEM-education and project activities are a means of developing leadership skills in students, which they will need in their future lives and careers.

\section{Conflicts of Interest}

The authors declare no conflicts of interest regarding the publication of this paper.

\section{References}

Andrievskaya, V., \& Bilousova, L. (2017). Interdisciplinary Approach to Teaching Primary School Students in the Format of STEAM-Education (pp. 17-25). Scientific Notes of the Small Academy of Sciences of Ukraine.

Balik, N. R., Leschuk, S. O., \& Friedrich, V. K. (2018). Development of STEM-Project “Mini Smart House”. http://ceur-ws.org/Vol-2546/paper14.pdf

Goncharova, N. O., \& Patrikeeva, O. O. (2020). Some Aspects of the Introduction of STEM Education. Information Collection for School Principal and Head of Kindergarten, 7, 5-8.

https://lib.iitta.gov.ua/721926/1/HONCHAROVA zbirnyk director 2020.pdf

Korshunova, I., Rhein, S., García-González, D., Stölting, I., Pfisterer, U., Barta, A., Khodosevich, K. et al. (2020). Genetic Modification Increases the Survival and the Neuroregenerative Properties of Transplanted Neural Stem Cells. JCI Insight, 5, e126268.

https://doi.org/10.1172/jci.insight.126268

Kramarenko, T. H., Pylypenko, O. S., \& Zaselskyi, V. (2019). Prospects of Using the Augmented Reality Application in STEM-Based Mathematics Teaching. Educational Dimension, 1, 199-218. https://doi.org/10.31812/educdim.v53i1.3843

Lucas, G. L., Cooke, F. W., \& Friis, E. A. (1999). Primer of Biomechanics. Springer Science \& Business Media. https://doi.org/10.1007/978-1-4419-8487-6

Morse, N. W., Gladun, M. A., \& Dziuba, S. M. (2018). Formation of Key and Subject Competencies of Students by Robotic Means of STEM-Education. Information Technologies and Teaching Aids, 65, 37-52. https://doi.org/10.33407/itlt.v65i3.2041

Morse, N., Wember, V., Boyko, M., \& Varchenko-Trotsenko, L. (2020). Organization of STEAM Classes in an Innovative Classroom. Open Educational E-Environment of the Modern University, 8, 88-106.

https://openedu.kubg.edu.ua/journal/index.php/openedu/article/view/307/312

Romanyuk, O. N., \& Poida, S. A. (2019). 3D Modeling in the Context of STEM. Proceedings of the International Scientific and Practical Conference "Information Technology in Culture, Arts, Education, Science, Economics and Business", Kyiv, 18-19 April 2019, Part 2, 110-112.

Schmiger, G. P., \& Vasilenko, J. P. (2017). Some Aspects of the Introduction of STEM Education in the Educational Process.

Yakman, G. (2019). STEAM-An Educational Framework to Relate Things to Each Other and Reality. 